\title{
The Application of Wood in Modern Interior Design
}

Dpen Access

\author{
Chang Lin*,\# \\ College of Furniture and Art Design, Central South University of Forestry and Technology, Changsha Hunan, 410004, \\ China
}

\begin{abstract}
Wood, which is well known as the most natural material, has been playing a very important role in the development of human society. The design concepts of promoting greens environmental protection have influenced the current society profoundly. As a culture carrier, the designing manner of using wood as the central element is very popular. The author is trying to dissect the beauty and the connotation of wood from the angle of Philosophy through this article. Then she will analyze the current use of wood in the modern interior design with examples. At last, the corresponding design principles and decoration methods will be summed up to combine with the actual situation of modern interior design.
\end{abstract}

Keyword: Culture carrier, modern interior design, spiritual connotation, wood.

\section{INTRODUCTION}

In recent years, more and more people begin to pay close attention to resource waste and environmental problems.Ecological economy and sustainable economy has become one of the hottest topics worldwide, and then under the background of this era, the ideological trend of "wood culture" has deep influences on the concept of modern interior design. People not only require a moderate, reasonable and beautiful design in the living environment, but also endow the interior design with more spiritual and moral appeal with the green, environmental protection and warmth. Wood is the oldest renewable natural resources used by the humankind, and also the most environmentally-friendly greenecological material. As a kind of cultural form, various wood art and wood products have rich cultural connotation and have become the important carrier of highlighting art taste and improving space cultural implication in modern interior design. So, the use of various forms of "wood" has become the common design method in modern interior design. The exploration and research on the combination of "wood" and interior design is very necessary. Close combination of both is of great significance to explore the cultural connotation of indoor environment.

\section{THE AESTHETIC CONNOTATION AND SPIRIT OF WOOD AND WOOD CULTURE}

Today, the category of modern interior design covers the original meaning of the adornment, including sound, light, electricity, heat and other physical environment and atmosphere, artistic conception and other psychological

\footnotetext{
*Address correspondence to this author at the College of Furniture and Art Design, Central South University of Forestry and Technology, Changsha Hunan, 410004, China; Tel: (+86)13707317105;

E-mail: 27162289@qq.com

\#Chang Lin (1981-), Female, a Lecturer and PhD candidate of College of Furniture and Art Design in Central South University of Forestry and Technology. Her research area: furniture design and interior project. Supported by Research Fund ofCentral South University of Forestry \& Technology.Project number:2013ZD04
}

environment and cultural connotation. From the philosophical level to understand "wood", we can more directly explore the role of its aesthetic connotation and spirit derivatives in the modern interior design as well as the application form.

In the historical process of human civilization, wood is not only a kind of objective existence, but also a civilization symbol with the natural ecological material as the carrier. It has survived thousands of years and has been condensed as a unique wood culture with the development of human civilization. William A. Havillandonce said in his book Cultural Anthropology, "culture is a society's shared and socially transmitted ideas, values, and perceptions, which are used to make sense of experience and which generate behavior and are reflected in that behavior." ${ }^{1}$ At the same time, as a domestic materials research scholar, Luo Jianju inhis thesis pointed out that as one of the cultural system, wood culture naturally includes these two dimensions ${ }^{2}$. The following two aspects can help us understand: firstly, for the culture, the basic conditions of any things being as culture include two: mental activity and material carrier, and the attribute of wood conforms to the conditions. Secondly, in terms of cultural ecology, wood culture is a secondary cultural system--using wood as the tie to connect social culture, aesthetic culture, architecture culture and living culture together, and forming a mesh natural material culture system, with other culture systems of wood as wrap and the wood material properties and spiritual attributes as weft. In the spiritual dimension of wood culture, the relationship between human and nature is the aesthetic core and the natural and material attribute of wood is the basic connotation of aesthetics. The former has the typical ecological characteristics while the latter has the characteristics of unity of heaven and man and personalization. Since ancient times, indoor and outdoor space of Chinese building are saturated with the concept of unity of heaven and man in all aspects and follow the con-

\footnotetext{
${ }^{1}$ William A. Havilland, Qu Tiepeng, Zhang Yu. Cultural anthropology[M].Shanghai: Shanghai Academy of Social Sciences Press.2006(5-6)

${ }^{2}$ Luo Jianju. An introduction to wood aesthetics[M]. Guangxi science and technology press, 2008-09
} 
cept of nature, which coincides with the aesthetic connotation of wood culture and provides theoretic support to find the spirit of wood as the main, common decoration elements in the interior design.

\section{THE APPLICATION STATUS OF WOOD IN MOD- ERN INTERIOR DESIGN}

Along with the development of the times, the concepts of green design and eco-friendly design are put into the modern design style which makes indoor design place more emphasis on environmental protection, resource saving, sustainable development and pollution abatement. Therefore, the design goal also becomes more humanized. The symbiosis of man and nature and the research of wood culture with wood as the carrier also become the mainstream and important thought foundation of the contemporary design industry. Specifically in terms of the characteristics of interior design with aesthetic as the core, the connotation of the spirit dimensions, performance characteristics as well as cultural significance of woodin the modern interior design, mainly includes the following aspects:

1) As a natural material, wood can build the ecological and natural beauty of the interior atmosphere.

2) As a sustainable material, wood can embody the social beauty of the cultural connotation in interior design.

3) Thanks to its structure and properties, wood can show the unique artistic beauty and humanity beauty by its design, pattern, color, texture elements etc.

4) Wood, with wooden building and wood products as the carriers, emphasizes the modeling beauty in the interior space through statuary art, three-dimensional construction art shaped by its rich modeling features.

5) Rosewood and other valuable timbers can enhance the sense of value of interior space.

In addition, from the perspective of the demand of mass at present stage, this paper analyzes the role of wood in the modern interior design from two aspects. As for the practical needs of consumers and in terms of simplicity design concept, the public prefer the design closely related to the nature and life. Because of its practicability and convenience, it will become more valued and be emphasized. Secondly, from the consumer psychology demand level, after the design can meet the practical needs of consumers, people tend to evaluate the design according to their personal taste and aesthetic standards. Wood has formed a certain aesthetic impression in people's minds for a long time. So, using the wood element in interior design becomes a necessary and inevitable trend.

The natural feeling and adornment effect of wood is irreplaceable; however, common wood has many disadvantages in stability, anticorrosion, insect resistance, fire resistance, moisture resistance and is difficult to provide all-round service for modern household life. Moreover, with forest resources dwindling, increasingly expensive solid wood products are gradually away from mass consumption in recent years. Especially nowadays, there are varied decorative styles and a lot of young consumers don't like the visual form of wood which is simple but has no variation. They prefer postmodern furniture with exaggerated color and dis- tinctive designs. Therefore, in the modern interior design, the wood elements have become less common.

\section{THE APPLICATION PRINCIPLE OF WOOD IN MODERN INTERIOR DESIGN}

In interior design, wood becomes the important raw material of the structure component and display in the interior space. At the same time, it isthe medium of the communication and dialogue between human and buildings and the indoor environment. According to the function and form of the wood elements, this paper discusses how to reasonably use the characteristic of wood itself in interior design and categorizes them. It employs reasonable analytical application method and design principles and provides practical guidance significance to explore the application of wood elements.

\subsection{Hard Decorate in the Form of Wooden Components}

In modern interior design, there are many common wooden components in various forms, mainly including: wood carving, wood trim, wooden mural, baluster, armrest, wood floor, skirting line, ceiling and wall body and so on. In Oriental classical architecture, there are numerous examples employing various forms of wooden components with beautiful structures as the main decoration. As shown in Fig. (1), it is a magnificent stone and painting works. In modern building decoration, we also often see various wooden "background wall" and wooden partition decoration in the porch place, which can be produced at the scene or be prefabricated in a factory and then assembled on site. These are typical wooden murals. In addition, wooden carving and other wooden components are also widely used in the interior, which generally contains two main parts --- building components and furniture. Their main art forms include doors, windows, planks, finches, hanging fascia, girders, lintels, isolated windows, window-sills, and the bed covers and cornices, the plates on the table, the backrest, handrail and accessories of chairs and so on. ${ }^{3}$

Along with the development of the era, people's aesthetic standard has been slowly changed. On the one hand, people yearn for simplification and personalization. On the other hand, they begin to add the appeals in the emotional level and expect their home space full of warmness, nostalgia and charm. Traditional wooden carvings have unique ancient building styles which make people in a happy mood, and then begin to be favored by the modern interior design but with more modern sense in use and decoration method. In general, wooden components need certain artistic processing, such as carving, inlaying, colored drawing, etc. Besides, wood can be used and combined with other materials in a number of simple and solid ways. These advantagesmake wood become one of the most commonly-used hard decoration materials. Most often, designers can make some changes of wooden components according to customer's different requirements and apply them into the facade space in modern aesthetic and hard outfit decoration techniques. Inlaying and hanging are the two most common techniques.

\footnotetext{
${ }^{3}$ Wang Xiao, Tao Yubo. Analyze the decorative art of traditional woodcarving tube plate [ J ] . Furniture \& Interior Design,2010,(6):88-89
} 


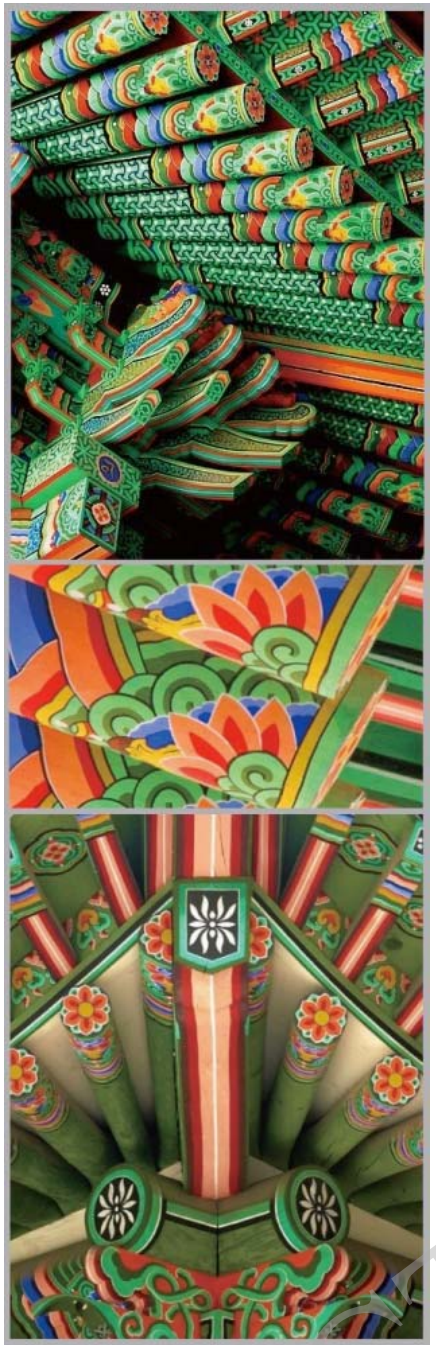

Fig. (1).

\subsection{The Soft Decorate Trend with Wood Accessories as the Carrier}

Those accessories mainly made of wood or wood materials (all kinds of natural or artificial materials with basic components of wood, such as natural bamboo, artificial wood plywood) are known as wood accessories. As a single product type, its material value and artistic value makes wood accessories high added-value product type. In the modern interior design, wood accessories have the following decorative features:

1) With the decorative features the interior space, wood accessories can make environmental forms richer, strengthen environmental artistic conception and modify atmosphere.

2) Wood has definite appreciating values, so wood accessories are available for people to fully enjoy and arouse association of strangeness, delicacy, interests, rich and high quality, etc. As shown in Fig. (2), American artist Dolan Geiman creatively used waste wood to design a dreamlike environmental art. Placing such an art work in any interior space will not only conform to the humanistic philosophy of environmental protection, but also be distinctive in style.
3) Since ancient times, wood accessories have the major characteristics of exquisite workmanship and fineness. Wood carving, wood engraving and other main forms of wood accessories have good manufacturability and collection value.

4) As a part of soft outfit display, some of wood accessories have both aesthetic function and practical function.

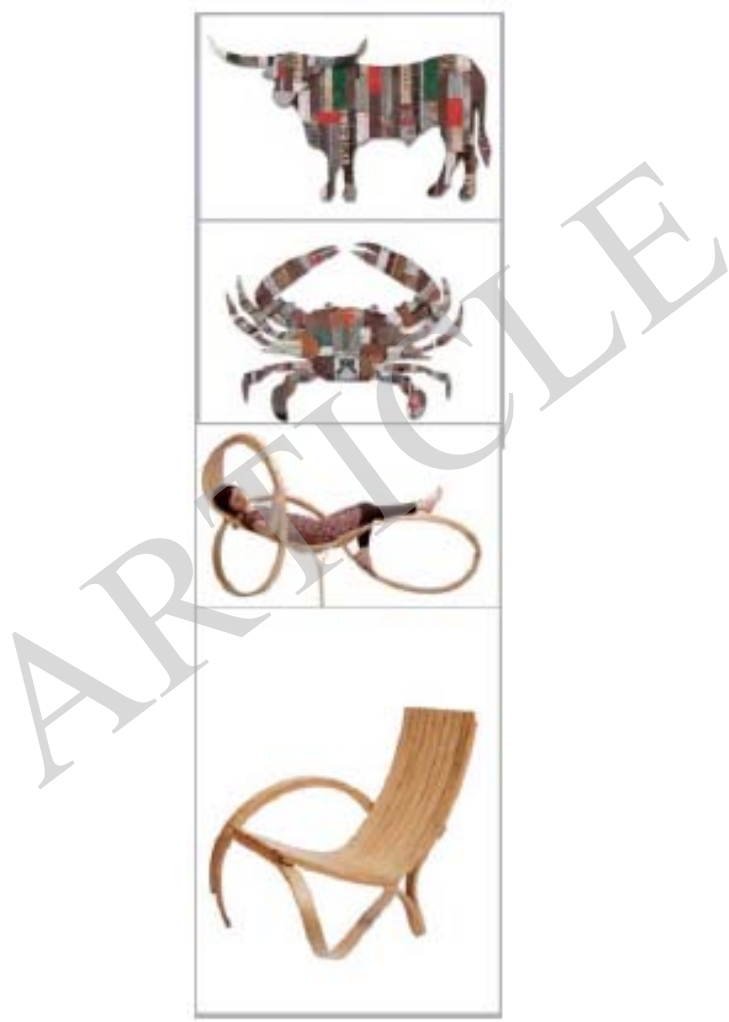

Fig. (2).

In recent years, interior design emphasizes the new design concept of weakening hard outfit and highlighting furnishings. Wood accessories enrich the indoor levels with their unique artistic images and artistic appeal and become important decorative items. Consumers, who cannot afford the complicated and expensive hard outfit decoration, can make full use of low-cost and high value-added small wood accessories to improve indoor atmosphere and meet individualized demands, and to add varied space effect, which accords with the development trend of modern soft outfit. For example, placing some flower tables or woodcarving in the corners of rooms not only can activate the whole corner and add some charm, but also can beautify the interior space. Most of the time, the texture and color characteristics of wood itself can make some simple furnishings. For example, in Fig. (3), wall ornament photos made of wasted birch have simple modeling and clean color, which both visually is fused with hard outfit style of modern design, and fills space requirement by functionality.

\subsection{The Space Function Demands with Wooden Furni- ture as the Main Body}

Furniture is a very important part of the indoor environment. If the architectural design gives architecture the first 
life, and then its second life is from the interior decoration, and the third life is given by the furniture ${ }^{4}$. Architecture is the outside while furniture is the inside. The former protects and is filled with the latter. The exterior-interior symbiotic relationship is reflected well in the modern interior space. "Wooden furniture" has two main functions in interior space; on the one hand, the wooden furniture can adorn a space atmosphere and emphasize the style characteristics with its workability and easily modeling beautification. Furniture can make up for the deficiency of too simple hard outfit without style, and also can highlight the unique style of household room. Meanwhile, the furnishings can embody the identity and cultural literacy of house owners. Its modeling brings certain artistic atmosphere to indoor environment and has considerable ornamental value. Fig. (4) shows, in the concise drab interior space, designers turn the wood into complex and beautiful three-dimensional furniture by the characteristics of its pliability, and make the internal space full of original, fashionable and active space atmosphere.

Fig. (3).

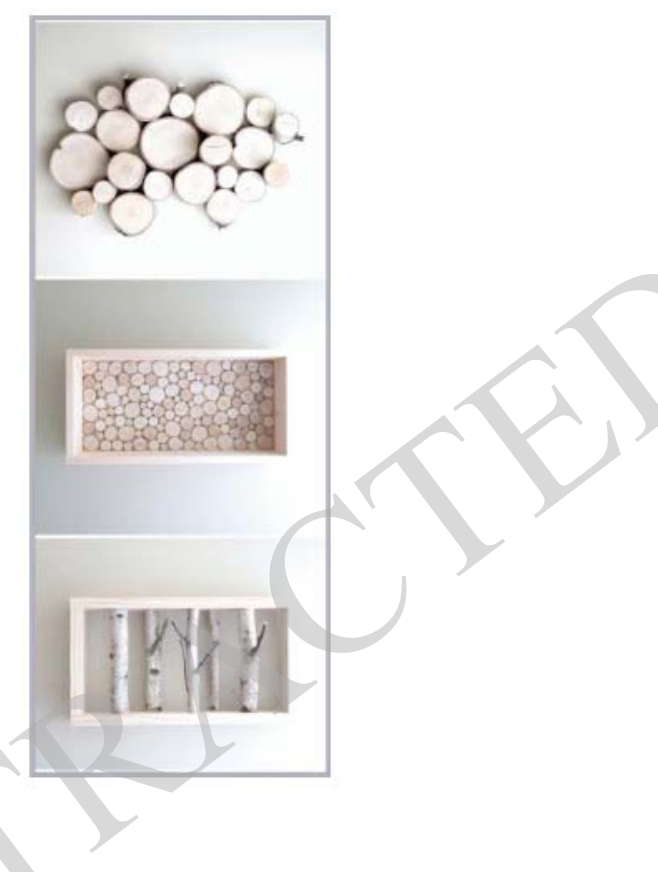

From another aspect, due to poor space form, the formed architectural space of ten limits its interior design. But furniture can help remedy the limitation of interior design, reshape architectural space to a large extent and divide the space. Take well-known wooden screen as an example, it is the unique element in traditional Chinese architecture, and is called $y i$ or fuyi in ancient documents. Wooden screen has not only rich aesthetic value, but also plays an unique role in the separation of interior space, the shape of space visual center and the construction of culture atmosphere. Because of arbitrary combination of its modularization for the space, modular-designed wooden furniture in modern design

\footnotetext{
${ }^{4}$ Zhao Xinshan. Architecture is a philosophical poem [ M ] . Baihua Literature and Art Publishing House. 2007

${ }^{5}$ Huo Weiguo. Study on characteristics of Chinese traditional architecture in interior design and decoration [ $\mathrm{J}$ ] Journal of NW Institute of Architecture Engineering (Natural Science). 2000
}

proved the theory that wooden furniture can satisfy the demands of space. As shown in Fig. (5), it is a perfect demonstration of endless table designed by Wenchuman in 2013 Milan furniture fair. In this work, the designer used the basic characteristics of various materials and made the distinction on colors. In interior design, we can imagine, distinguishing the function and range of furniture with colors is also a new attempt and idea. Therefore, applying wooden partitions, wooden screen and other more functional wood elements into interior designs, is a perfect way to solve space appeal.

Fig. (4).

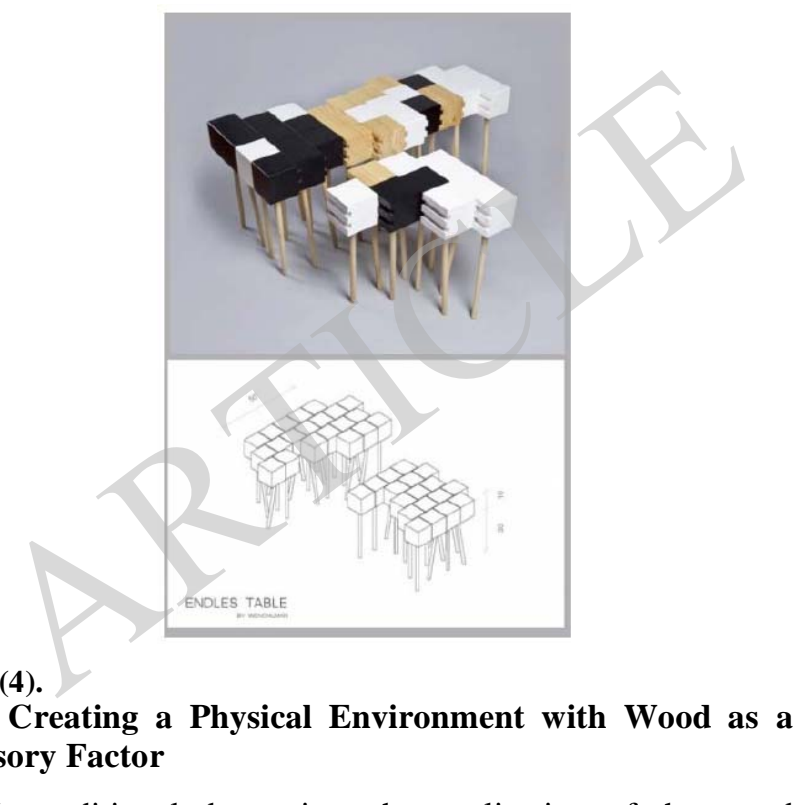

In traditional decoration, the application of the wood element involves a problem of aesthetic value: sensory pleasure of users and emotional expression of designers. Perception is a part of our biological nature. In terms of the performance of the interior space, in addition to the human body comfort caused by wood perfect function, the visual effects, tactile sensation and artistic conception of wood itself are also the key point of modern interior design, and the demands in spiritual level become even more important in today's consumer market. Furthermore, wood has both the physical characteristics of easily processing and the touch feeling of its tender texture, which can help to create a physical environmental atmosphere in interior design.

In interior design, the visual characteristics of wood people stress mainly refer to the color, reflection, absorption and decorative pattern of the wood, and their effects on human physiological and psychological comfort. For example, the same color of dyed wood as red sandalwood and rosewood can make people feel grand and profound; wood with high lightness can make a bright, clean and beautiful impression while the lightness is decreased by colorant, there will be steady, deep and elegant. Wood of low chroma let people feel simple but elegant, messiness and calm while wood of high chroma make a luxuriant, exciting and luxurious feeling. Wood can absorb ultraviolet light to reduce its harm radiation to human beings, and reflect infrared rays to bring warmth to people ${ }^{6}$. Wood has the characteristics of diffuse

\footnotetext{
${ }^{6}$ The basic characteristics of the timber and its good visual features.http://www.woodscien.com
} 
reflection and fine luster. The luster of wood refers to the brightness of light reflection on the wood and is connected with tree species, wood structure characteristics, and the reflection angle of light beam on extracts and sediments, the cut surface of the wood and other factors. If users expect to acquire a peaceful relaxation and release pressure at home after their busy work, we can use light-colored wood with soft natural texture and exquisite wood texture to decorate the interior space, such as birch, beech and maple which are quite common in the Nordic design. On the contrary, if people want a home atmosphere with cultural charm and scholarly elegance, some wooden carvings can be applied in hard outfit patterns, especially such as the quaint, traditional and dark annatto. With a certain cognitive, designers can flexibly choose the wood elements from its colors, texture and patterns, and create the physical environment atmosphere according to user's sensory and mental demands. It is the unique natural attribute that distinguishes wood from other basic decorative materials.

\section{CONCLUSION}

Louis Kahn once put forward that designers must know the sequence, "when you look at a brick, or do designs about it, you must ask the brick what it wants to be, or what it can do..." The sequenceis to fully understand the nature, connotation of the material and then to adapt the best ways according to their attributes. As the most common design material, wood can express a certain cultural aesthetic and spiritual pursuit by its material, modeling, color, texture and modeling of individual space in the long design practice, which accords with the characteristic demands of the modern interior design. To sum up, analyzing the wood culture with wood as the carrier from the perspective of the aesthetic connotation and spiritual derivatives is to further seek for the principles corresponding to the modern interior design, and to provide theoretical guiding significance for the interior design.

\section{CONFLICT OF INTEREST}

The author confirms that this article content has no conflict of interest.

\section{ACKNOWLEDGEMENTS}

Declared none.

\section{REFERENCES}

[1] H. William, T. Qu, and Y. Zhang, "Cultural anthropology," Shanghai: :Shanghai Academy of Social Sciences Press, no.5-6, 2006.

[2] J. Luo, "An introduction to wood aesthetics," Guangxi science and technology press, 2008-09.

[3] X. Wang, and Y. Tao, "Analyze the decorative art of traditional woodcarving tube plate," Furniture \& Interior Design, no. 6, pp. $88-89,2010$.

[4] X. Zhao, "Architecture is a philosophical poem," Baihua literature and art publishing house, 2007.

[5] Y. Li, and J. Li, "The soul of interior design: furniture," Big stage, pp. 99-99, 2011.

[6] J. Shen, "The application of Chinese traditional cultural elements in modern indoor design," Shanxi Architecture, no. 35, pp. 43-44, 2009.

[7] W. Huo, "Study on characteristics of Chinese traditional architecture in interior design and decoration," Journal of NW Institute of Architecture Engineering (Natural Science), 2000.

[8] J. Wang, "Introduction to decorative materials application in interior design," Science and Technology Innovation Herald, no. 19, 2009.

[9] Z. Yang, "On the design of architecture and the natural indoor beauty," Journal of Chengdu Textile College, no. 01, 2001.

[10] L. Wang, "Back to the beauty of the wood in interior design," China Construction News, 2009.

[11] "The basic characteristics of the timber and its good visual features," http://www.woodscien.com

[12] Y. Bao, "Indoor application and sustainable development thought of woodiness material environment," Sichuan Architecture, no. $12,2008$.

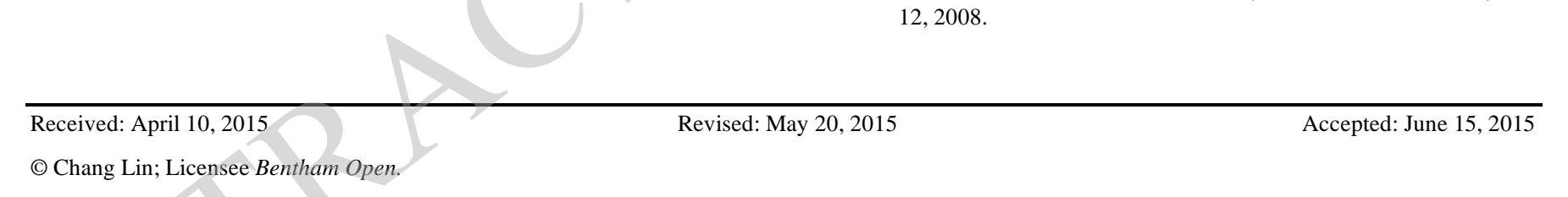

This is an open access article licensed under the terms of the (https://creativecommons.org/licenses/by/4.0/legalcode), which permits unrestricted, noncommercial use, distribution and reproduction in any medium, provided the work is properly cited. 